\title{
A VIVENCIA DE UM ESTUDANTE DE ENFERMAGEM EM UMA EQUIPE INTERDISCIPLINAR: FÁBRICA DE IDÉIAS*
}

\section{THE UNDERGRADUATE NURSING STUDENTS EXPERIENCE AS A MEMBER OF A MULTIDISCIPLINARY TEAM; FACTORY OF IDEAS}

Sylvia Vaie**

Sônia Barros***

\begin{abstract}
VAIE, S.; BARROS, S. A vivência de um estudante de enfermagem em uma equipe interdisciplinar: fábrica de idéias. Rev Esc Enf USP, v. 35, n.2, p. 100-7, jun, 2001.

\section{RESUMO}

A experiência do Estágio Curricular em um serviço de atendimento à saúde mental, extra-hospitalar, o CAPS, levou ao desenvolvimento deste estudo na tentativa de entender e caracterizar uma equipe interdisciplinar nesta instituição, assim como, compreender a inserção de uma estudante de enfermagem nesta equipe. A análise das respostas revelou que nos discursos, encontra-se o conceito de interdisciplinaridade assim como o de multidisciplinaridade (trabalho compartimentado). A concepção que se tem do modelo assistencial e da inserção do projeto neste modelo, é compativel com as noções que fundamentam a descrição do serviço: flexibilidade, inter-relação dos projetos, a clinica ampliada e a reabilitação psicossocial. O fato do serviço ter um Programa de Integração Docente-Assistencial, "naturaliza" e valida a participação de uma estudante de enfermagem nos projetos assistenciais ou de sociabilidade.
\end{abstract}

PALAVRAS-CHAVE: Equipe de assistência ao paciente. Saúde mental. Enfermagem psiquiátrica.

\begin{abstract}
The experience of the Curricular Training in a mental health work attendance to out-patients, CAPS, lead to this study development in the attempt to understand and characterize interdisciplinary team in this institution, as well as to understand the admittance of a nursing student in this team. The analysis of the replies disclosed that in the reports is found the concept of interdiscipline as well as of the multidiscipline (work in compartments). The conception with has of the model of assistence and of the admittance of the project in it is compatible with the conceptions that establish the description of the work: flexibility, the projects inter-relation the enlarged practice and the psychosocial rehabilitation. The fact that the service has a Program of lecturing-Assistence Integration, "naturalizes"and validates the participation of a nursing student in the projects of assistance or sociability.
\end{abstract}

KEYWORDS: Patient care team. Mental health. Psychiatric nursing.

\section{INTRODUÇÃo}

Este estudo foi desenvolvido durante a disciplina "Estágio Curricular em Enfermagem Materno-Infantil e Psiquiátrica", a qual é oferecida no $8_{-}^{\circ}$ semestre do curso de Graduação em Enfermagem da EEUSP e o aluno escolhe um campo de estágio para desenvolver as suas atividades, incluindo a realização de uma monografia de conclusão de curso.

A escolha recaiu no Centro de Atenção Psicossocial Professor Luís da Rocha Cerqueira CAPS., pois a autora tinha que transformar de alguma forma o mal estar, a má impressão que a pessoa com doença mental, na instituição asilar, lhe causara.

O CAPS, inaugurado em 1987, é uma estrutura de atendimento à saúde mental, substitutiva à hospitalocêntrica, e tem como finalidade oferecer tratamento a pessoas acometidas por doença mental. O projeto CAPS tem se desenvolvido e ampliado a partir do cotidiano clínico da unidade, em função das questões que os tratamentos continuamente apresentam (BARIÇÃO, 1994).

* Trabalho apresentado na dísciplina Estágio Curricular, para conclusão do curso de Graduação em Enfermagem, na EEUSP, em dezembro de 1997.

** Enfermeira. Aprimoranda do Curso de Saúde Mental CAPS/FUNDAP

*** Professora Doutora da disciplina Enfermagem Psiquiátrica da EEUSP. 
Em 31 de outubro de 1996, foi firmado um convênio entre a Universidade de São Paulo, através do Departamento de Medicina Preventiva, do curso de Terapia Ocupacional da FMUSP e da disciplina Enfermagem Psiquiátrica da Escola de Enfermagem da USP, e a Secretaria de Estado da Saúde do Estado de São Paulo com o objetivo de desenvolver um Programa de Integração Docente Assistencial em Saúde Mental (PIDA), cujo "locus" de ação é o CAPS.

Este Programa privilegia a Reabilitação Psicossocial como campo de práticas e conhecimentos, considerando a capacidade dos sujeitos acometidos de transtornos psiquiátricos graves de construir uma possibilidade de contrato psicológico e social com o meio exterior (PITTA et al, 1994).

O Programa incorporou também o Ambulatório Centro, localizado ao lado do CAPS, que passou também a fazer parte do Modelo Assistencial proposto.

O PIDA é gerenciado por um Conselho Administrativo, com representação da Universidade, da Secretaria e da Comunidade através da Associação Franco Basaglia (AFB) que agrega usuários do serviço e

seus familiares.

No CAPS são realizados diversos grupos terapêuticos e de projetos especiais diaria-mente, coordenados por uma equipe interdisciplinar formada por psiquiatras, psicólogos, enfermeiros, assistentes sociais, terapêutas ocupacionais, aprimorandos em psicologia e em enfermagem e, também, por trabalhadores do grupo de apoio. O que chama a atenção, particularmente, é o trabalho desenvolvido pela enfermagem, onde enfermeira e auxiliares compõem a equipe e, sem perder suas especificidades, realizam um trabalho bem diferenciado do hospitalar, onde a enfermeira, na maioria das vezes, é identificada pelo seu uniforme e não, pelo seu trabalho.

O estágio curricular foi realizado de agosto a novembro de 1997. Durante esse período, participamos de alguns grupos no CAPS, tais quais: grupo de final de - semana, grupo de acolhida, grupo de projetos, reunião com o grupo de trabalho da copiadora, reunião geral dos usuários, reunião técnica do núcleo intensivo, supervisão com o pessoal de apoio e grupo 'fábrica de idéias'.

Neste estudo, vou ater-me, especificamente, ao grupo 'fábrica de idéias', que ocorre semanalmente e tem uma hora e meia de duração. Coordenado por uma equipe multiprofissional, é recém-iniciado (há aproximadamente três meses) e contava, principalmente, com a participação de usuários psicóticos. O que chamou a minha atenção neste grupo, é o fato da interdisciplinaridade da coordenação transcorrer de forma tão simples; os coordenadores agem basicamente da mesma maneira. Parece que um quarto membro - a junção destes três, coordena o grupo, mesmo havendo uma aparente divergência entre os coordenadores (talvez por terem diferentes formações), no que tange a alguns conceitos, concepções e referenciais teóricos. A nossa inserção neste grupo não trouxe, aparentemente, questões ou dificuldades para os coordenadores, assim como, percebemos que para eles o papel da enfermeira nesta instituição é de contato direto, de cuidados intensivos aos pacientes em diversas situações e espaços, como em grupos, e não somente restrito à medicação, por exemplo, como maioria das instituições que lidam com pacientes graves, onde a enfermeira fica responsável por esse tipo de cuidado.

Mas, o que a literatura nos diz, de acordo com FILIZOLA (1990), AMARAL (1990), ROCHA (1992) é que a prática do enfermeiro em serviços de saúde mental é burocrático-administrativa, incluindo a supervisão do pessoal auxiliar, enquanto as escolas de enfermgem vêm enfatizando o papel do enfermeiro como terapeuta.

No entanto, também observa-se o trabalho inovador que vários enfermeiros vêm realizando em serviços de saúde mental, atendendo a um novo paradigma construído no processo da Reforma Psiquiátrica. Isso faz supor que o preparo para o exercício profissional do enfermeiro psiquiátrico tem se dado no próprio mercado de trabalho já que, em tese, o ensino de enfermagem não incorporou em suas práticas ações baseadas no novo paradigma contido na atual política de Saúde Mental (BARROS, 1996).

Portanto, como afirmam ALMEIDA; ROCHA (1986), não é somente a complexidade do saber que irá definir o. que cabe ao enfermeiro fazer, mas sim, o próprio desenrolar da prática de enfermagem no conjunto das práticas de saúde.

Tendo em vista essas observações, a experiência e as concepções apreendidas durante o estágio, foi proposto neste estudo investigar alguns aspectos do trabalho em equipe, que estão expressos nos discursos dos trabalhadores, visto que o trabalho em equipe multiprofissional é um dos princípios da Reforma Psiquiátrica, em processo no nosso país.

Assim, os objetivos deste trabalho foram:

\section{Caracterizar uma equipe interdisciplinar;}

2.Identificar a concepção dos membros desta equipe, acerca do modelo assistencial desenvolvido no CAPS;

3.Analisar o processo de inserção de um estudante de enfermagem em uma equipe interdisciplinar de uma instituição de Saúde Mental. 


\section{METODOLOGIA}

Este é um estudo descritivo, porque permite uma aproximação e descrição da situação focalizada, ou seja, a questão da interdisciplinaridade em um determinado modelo assistencial.

"A pesquisa exploratória inicia-se por algum fenômeno de interesse, busca explorar as dimensões desse fenômeno, a maneira pela qual ele se manifesta e os outros fatores com os quais ele se relaciona" (POLIT; HUNGLER, 1995).

Como já foi mencionado, este estudo foi realizado no Centro de Atenção Psicossocial Professor Luis da Rocha Cerqueira (CAPS) localizado à Rua Itapeva, número 700, bairro Jardim Paulista, em São Paulo.

O grupo 'fábrica de idéias' é um dentre muitos grupos realizados no CAPS, e é especificamente ele que foi estudado.

O projeto desse grupo foi idealizado por três profissionais de formações diferentes, cujas opiniões e concepções eram muito parecidas; assim surgiu a proposta de complementar umas às outras e formouse este grupo.

O grupo ocorre semanalmente, todas as quartas feiras, tendo uma hora e meia de duração. Conta com oito a dez pacientes por sessão, com "perfis" diferentes idade, sexo, comportamento, etc. A idéia inicial do projeto foi a montagem de uma caixa contendo sucatas tais como: papéis, cartolinas, papelão, isopor, caixas; e, ainda, de uma outra caixa onde são colocados os trabalhos produzidos, podendo os mesmos serem retomados nas semanas seguintes por seus autores. Os materiais, tais como, tintas, canetinhas, palitos de sorvete, revistas, são a matéria - prima para que algumas idéias sejam "fabricadas" (este material fica num armário na sala aonde é realizado o grupo). Cada participante idealiza e realiza o que tem vontade e com o passar do tempo, a integração e a cooperação entre os usuários foi tornando-se visivel, como incentivos e elogios mútuos ao trabalho realizado, à trabalhos que estavam começando a ser realizados em conjunto.

Os coordenadores do grupo fábrica de idéias' são os sujeitos deste estudo. São três técnicos, dois do sexo feminino e um do sexo masculino. Trabalham na instituição há pelo menos quatro meses, e foram os idealizadores do projeto. Têm formações profissionais diferentes, como já foi mencionado: um terapeuta ocupacional, um psicólogo e um psiquiatra.

Para as entrevistas foi elaborado um formulário contendo cinco itens para a caracterização do profissional:

1.nome;

2. profissão;

3.tempo de trabalho nesta instituição; 4.atividades realizadas após a graduação;

5.referencial teórico que utiliza.

Contendo também, outras cinco questões mais abrangentes (ANEXO).

Os três coordenadores foram entrevistados com a utilização de um gravador. Os objetivos da entrevista e do estudo foram devidamente esclarecidos e houve consentimento por parte dos entrevistados. E necessário salientar que os nomes dos entrevistados foram omitidos, cada um, aleatoriamente, foi denominado: A, B, C.

As entrevistas tiveram duração média de trinta minutos cada uma e ocorreram no período de 30 de outubro a 06 de novembro de 1997.

Para a análise dos dados buscou-se como referencial a análise de conteúdo "na busca de atingir os significados manifestos e latentes no material qualitativo" (MINAYO, 1992).

Entre as técnicas de análise de conteúdo, tentou-se uma aproximação com a análise temática, a qual, segundo MINAYO (1992), "consiste em descobrir os núcleos de sentido que compõem uma comunicação cuja presença ou frequência signifiquem alguma coisa para o objetivo analítico visado.(...) Se encaminha para a contagem de frequência das unidades de significado como definitórias do caráter do discurso".

Baseadas, então, nos passos descritos pela autora citada acima, inicialmente lemos exaustivamente o material, assinalando o que, em cada resposta, era significativo para a questão feita.

Após, constituímos as unidades de contexto, que foram relidas e, então, extraímos as .unidades de registro para a análise.

A categorização dos dados foi determinada pelas próprias questões realizadas. Assim, as categorias empiricas, ou seja, aquelas construídas com finalidade operacional foram assim definidas:

1.A interdisciplinaridade;

2.A produção do projeto;

3.Modelo do CAPS;

4.Enfermeiro e a equipe.

Vale salientar que devido ao curto período para realização deste estudo, não foi possivel abranger muitos aspectos e melhor interpretar todos os dados, devido a sua riqueza.

\section{RESULTADOS}

\section{A QUESTÃO DA INTERDISCIPLINARIDADE}

Segundo SILVA e FONSECA (1993), repensar a interdisciplinaridade na assistência à saúde mental 
não se limita a repensar a forma com que isto tem se dado, mas, além disto, analisar a sua essência, ou seja, as bases conceituais sobre as quais tem sido construído o conhecimento que embasa a prática interdisciplinar, e que, em última instância, traduz a visão de mundo que permeia o modelo de atenção instituído.

Por visão de mundo compreende-se um conjunto de conceitos e valores que dão suporte e norteiam a atividade humana, neste caso, determinada prática profissional.

Quando os entrevistados relacionam a interdisciplinaridade com especificidade, percebe-se a concepção do modelo positivista, que segundo SILVA e FONSECA (1993) "determina a possibilidade. de universalização dos resultados das investigações e a universalização das práticas. A relação entre as partes que se estabelece a partir da divisão do todo através do método dedutivo, possibilita a identificação de especificidades de atuação em cada área profissional"

"...nem pode existir um ideal de que todos são terapeutas porque não são, tem que haver uma formação, e cada um com sua formação pode estar contribuindo." (sujeito A)

Segundo CAMPOS (1990), "não há dúvida que, especificamente na área de Saúde Mental, sobretudo nos serviços públicos, não existem reais equipes de trabalho interdisciplinar e sim profissionais de diversas áreas de conhecimento, desenvolvendo suas atividades numa instituição sem que haja por parte desta, definição de uma proposta de trabalho voltada para um objetivo comum. As ações desenvolvidas, que têm como alvo o paciente, com frequência carecem de articulações e se perdem ou se diluem por se somarem, justaporem ou mesmo se contraporem."

A mesma autora afirma que o trabalho interdisciplinar não é estático, nem compartimentado. Multidisciplinaridade e interdisciplinaridade devem caminhar juntas. Refere, ainda, que muitas vezes chama-se de equipe interdisciplinar, o que na realidade é um agrupamento de profissionais de áreas diferentes. Um grupo de profissionais só configura uma equipe interdisciplinar quando opera de modo cooperativo, convergindo seus objetivos para uma dada situação, de forma a haver complementariedade e não soma ou superposição.

Operar de modo cooperativo, por sua vez, não implica em trabalhar sem conflitos. A presença de conflitos é inevitável e universal. A seguinte frase temática, extraída do discurso parece ilustrar este texto:

"... é uma composição de saberes... sem perder a especificidade de cada um. Compõe um determinado tipo de intervenção." (sujeito A)
Pode-se perceber a possibilidade de conflito na frase temática que segue:

"Ficar responsável por uma disciplina... o que tem que haver realmente é uma questão única em que todos esteja minimamente de acordo, apesar de cada um ter sua linha." (sujeito B)

Há um consenso quanto a importância da interdisciplinaridade, mesmo que haja uma certa distorção em sua concepção teórica, aproximando-a e até confundindo-a com a multidisciplinaridade.

Há desvinculação do modelo positivista, pensase no modelo dialético, que "pressupõe, numa relação dos diferentes profissionais da área da saúde entre si e destes com a clientela, a possibilidade de transformação de ambos durante todo o processo terapêutico. Necessariamente, a partir da visão desse vínculo, profissionais entre si e profissionais e população são atores e autores, em constante processo de transformação" (SILVA; FONSECA, 1993). Como se pode ver na frase temática abaixo:

"...não ter um trabalho compartimentado... ter uma influência entre os vários saberes." (sujeito $C$ )

$\mathrm{E}$, ainda, que apareça divergência conceitual nessa equipe, o trabalho em si e o modo de analisar o grupo em cada reunião realizada antes do início do projeto (semanalmente), traduzem uma compatibilidade e uma reciprocidade tamanha, que chega a ser dificil, em alguns momentos, diferenciá-los profissionalmente. É como se cada um deixasse sua especificidade de lado e 'vestisse uma nova camisa', compondo um terapeuta novo, um terapeuta que age e pensa de um só modo, mesmo sendo composto por três pessoas. Esta compreensão pode ser inferida na frase temática abaixo:

"Acho importante ter a questão da especificidade, mas na hora do grupo isso não aparece... se faz um trabalho de coterapia" (sujeito C)

Identifica-se, assim, uma prática que "superando a preconização da assistência pela prática médica, a coletivização do projeto terapêutico não pressupõe a perda da identidade profissional, mas a relativização da prática específica, no coletivo" (FONSECA, 1993).

\section{A PRODUÇÃO DO PROJETO "FÁBRICA DE IDÉIAS"}

Em relação ao surgimento do grupo e a produção do projeto, cada qual, a sua maneira, visa a concretização de idéias, de delírios, de ações ou desejos mínimos dos usuários. Mas para todos, o que importa é a realização da expressão, efetivação da criação, principalmente para os psicóticos. Ou seja, a idéia do projeto... 
"...rola na dinâmica interpessoal, contrato paciente/paciente, paciente/terapeuta... um movimento de produzir subjetividade... subjetivar-se objetivando". (sujeito B)

Ou ainda, ele nasce a partir de:

"...possibilidades de expressão ou de produção (...) falar ou escrever alguma coisa, desde uma idéia totalmente imaginária para uma mais próxima do concreto, e metáfora delirante seria a ratificação do delírio." (sujeito A)

E o grupo coordenador:

"...surgiu da questão da transdisciplinaridade... do que os pacientes estavam precisando, a idéia parte da necessidade deles... Ampliar sua visão de mundo". (sujeito $\mathrm{C}$ )

Ao se falar dos objetivos definidos para o projeto, têm - se basicamente dois caminhos:

- As relações entre os membros da equipe, entre os próprios pacientes e entre terapeutas/pacientes. Dizem respeito ao modelo do CAPS e levam em consideração o ato de fazer ligações entre projetos e entre pessoas:

"É fazer a liga, não só entre profissionais, mas entre projetos, para se ter um projeto de trabalho em conjunto." (sujeito B)

"É trabalhar as relações" (sujeito C)

- Instrumentalizar o paciente, para que este desenvolva questões e produza trabalhos mais próximos do concreto. $\mathrm{O}$ que aparece na seguinte frase temática:

"Construir, propiciar um espaço de produção, de vários caminhos". (sujeito A)

\section{O MODELO CAPS}

A reforma psiquiátrica em andamento no Brasil propõe, entre outras ações:

- Diversificar as possibilidades na oferta de serviços, superando a crença consolidada de que o hospital psiquiátrico é o lugar ideal para o tratamento das pessoas com transtornos mentais;

- Oferecer no hospital psiquiátrico, enquanto ele existir, tratamento e não confinamento e martírio, que sempre foram marcas desses serviços;

- Respeitar e ampliar os direitos das pessoas com transtornos mentais, incorporando-as como sujeitos no processo de superação de suas dificuldades.

Dentre estas propostas de reformulação, como já foi descrito na introdução deste trabalho, o CAPS tem sua base numa proposta de atendimento diferenciado, de trocas sociais, de múltiplas possibilidades, constituida por uma equipe multiprorfissional (GOLDBERG, 1996).
A função mais importante é receber cada pessoa do jeito que é, garantindo sua particularidade.

Percebe-se isso nesta frase temática, presente no discurso de um dos técnicos do projeto:

"... criar uma condição de que ele possa ser sujeito dentro de todas as limitações. "(sujeito A)

".. a partir das idéias dele, o que dá para se fazer enquanto ser ativo que produz coisas." (sujeito B)

O tratamento visa, dentre muitos aspectos, que o universo de problemas de cada um ganhe um relevo todo especial, que seja protagonista da situação institucional.

Acolher um paciente pela primeira vez, por exemplo, não é estar do outro lado de uma mesa, observando o comportamento, mas estar disposto a recebê-lo e estar com ele na situação, participando, tentando apreender um código desconhecido.

\section{"... De forma a dar continência para o sofrimento psíquico dele." (sujeito $\boldsymbol{B}$ )}

A instituição procura proporcionar um número grande de projetos, uma circulação intensa de experiências que atendam aos pedidos dos usuários: "A preocupação central é que possam sedimentar uma cultura, um ambiente capaz de ser falado (compartilhado), provendo um suporte para que as questões apareçam. As psicoterapias grupais e individuais podem ser o lugar no qual tais questões podem ser trabalhadas" (GOLDBERG, 1996).

Quando o modelo do CAPS e o projeto 'fábrica de idéias' são relacionados, surge uma idéia central de que o projeto é um molde menor, uma "maquete" do CAPS; é feita uma vinculação imediata na seguinte frase temática:

"O fábrica" se insere no modelo do CAPS, na questão da criatividade que o CAPS tem... Estamos exatamente nesse meio, que não é nem lá no terapêutico e nem no social, no mundo. É fazer uma intermediação". (sujeito A)

Segundo BERG (1981) "a relação entre o homem e o mundo é tão íntima que seria errado separá-los, num exame psicológico ou psiquiátrico. Se forem separados, o paciente deixará de ser o seu mundo... Se desejarmos compreender a existência humana, teremos que prestar ouvido à linguagem dos objetos. Se estivermos descrevendo um sujeito, teremos que elaborar a cena na qual o sujeito se revela."

Pessoas que saem sozinhas, participam de atividades, podem surpreender profissionais e familiares com iniciativas que estavam adormecidas. Isto surge nesta frase temática: 
"Oferecer possibilidades para que esse sujeito se constitua como tal, em relação a sua vida social ou suas questões subjetivas." (sujeito B)

"A perspectiva do tratamento dessas pessoas tem como objetivo proporcionar que atinjam patamares cada vez mais altos de gerenciamento de suas vidas, possibilidades sempre maiores de autonomia, qualquer que seja a medida destas para eles" (GOLDBERG, 1996:44).

"Ir resgatando um sentido para aquela pessoa com tratamento, que ela possa se apropriar de algumas coisas, da vida dele." (sujeito C)

Revendo esses comentários e as frases temáticas, fica claro como instituições com este tipo de modelo de atenção são válidas, eficazes e devem continuar crescendo, se multiplicando.

\section{O ENFERMEIRO E A EQUIPE INTERDISCIPLINAR}

Segundo BARROS (1996), o enfermeiro tem dificuldade em assumir atividades assistenciais e trabalhar em equipe.

Porém, "tem-se como pressuposto básico que a prática da enfermagem, em uma instituição que permite confrontar constantemente o instituído com o instituinte, possibilita ser uma atividade humana criadora, efetiva, compartilhada, ou seja, uma atividade de construção/desconstrução que se expressa através de relações com outras práticas sociais, com usuários e familiares" (OLIVEIRA; JORGE; SILVA, 1996).

$\mathrm{E}$, ainda, "a enfermagem inserida numa nova modalidade de atendimento possibilita redimensionar a sua relação com as demais práticas sociais no campo da saúde mental e com a clientela, ampliar seu universo de conhecimento específico, que admita o questionamento do saber/poder tradicional herdados a partir do fracionamento do trabalho médico" (SILVA; FONSECA, 1993).

Nos relatos da equipe do "fábrica de idéias", é possivel identificar uma certa despreocupação com a especificidade profissional. A entrada e a participação de um estagiário no grupo é válida, qualquer que seja sua formação, reiterando a noção de interdisciplinaridade, como percebe-se nesta frase temática:

"Não se pensa em especialidade... se pensa que tem que ter um aprimoramento para que o futuro profissional saiba o que é o trabalho interdisciplinar A fábrica não obriga nenhuma especialidade é saber trabalhar essa prática interdisciplinar". (sujeito $C$ )
"Uma enfermeira numa instituição de reabilitação psicossocial vai se firmando na ação compartilhada com outras práticas sociais e no vínculo que estabelece com o usuário" (OLIVEIRA; JORGE; SILVA, 1996).

PEPLAU, em 1962, já considerava o papel de psicoterapeuta como o ponto crucial da Enfermagem Psiquiátrica e, os demais, como subpapéis.

Levando-se em conta que em 1962 este caminho para o enfermeiro já estava trilhado, é curioso quando se percebe nos discursos destes técnicos que a área da Saúde Mental, é uma nova opção para a enfermeira:

"Na formação da enfermagem tem mais essa possibilidade de trabalhar a questão da saúde mental." (sujeito $C$ )

"É uma profissão que pode ir para vários âmbitos." (sujeito B)

E há a importância da questão interdisciplinar, evidente nas seguintes frases temáticas:

"Apesar das diferentes profissões, há um intuito comum no jeito de lidar com as diferenças de experiências." (sujeito A)

"Ter essa experiência interdisciplinar é fundamental." (sujeito $C$ )

E quanto à participação de um estudante de enfermagem, especificamente, tem-se o seguinte:

"Eu acho fantástico... compõe uma outra visão, um outro olhar," (sujeito $C$ )

"Acho bem interessante, acho que você acaba entrando um pouco nessa composição." (sujeito B)

Essas frases temáticas vêm ao encontro do que GOLDBERG (1996:42) afirma: "um trabalho com o perfil do que é desenvolvido no CAPS, só pode acontecer juntamente com uma proposta de ensino e pesquisa, associando-se à Universidade para formar alunos da graduação no âmbito dessa proposta".

Isso aparece, também, em uma outra frase:

"Todos os projetos da casa têm um espaço para o ensino ... aqui têm um trabalho que permeia o trabalho - escola." (sujeito A)

Segundo BARROS (1996), entende-se que a mudança na qualidade de assistência à saúde passa, também, pelo redirecionamento da qualificação da força de trabalho em saúde e, que as escolas têm responsabilidades na formação de atores comprometidos com projetos de transformação.

A mesma autora afirma que a consciência da contradição entre o saber produzido nas Escolas e o fazer, e a necessidade da apreensão e construção de novas concepções e de novas práticas interventivas em saúde mental é que determinou que os docentes da 
disciplina Enfermagem Psiquiátrica tornassem-se participes de uma proposta de PIDA - Saúde Mental no CAPS -ltapeva, buscando superar o modelo tradicional de ensino e de assistência na enfermagem psiquiátrica.

"Este novo cenário da saúde mental exige um processo de ensino - aprendizagem criativo/reflexivo na área de enfermagem psiquiátrica que possibilite às enfermeiras referenciais/instrumentais de ação e a construção de estratégias que dêem conta da multidiciplinaridade para abordar as formas de adoecimento mental. E preciso questionar o ensino atual, buscar a unidade teórico/prática, enfim, fazer emergir o paradigma ou um conhecimento prudente para uma vida decente" (SANTOS, 1988).

\section{CONSIDERAÇÕES FINAIS}

O período que compreendeu o Estágio Curricular e o desenvolvimento da monografia foi muito rico.

Em todos os grupos que participamos fomos muito bem recebidas, tanto por parte dos técnicos e aprimorandos, como dos usuários. Era curioso o fato de um grupo ser coordenado por uma assistente social e uma enfermeira, por exemplo. Ficava mais curioso quando descobria-se suas formações, pois para nós, todos eram psicólogos até que se provasse o contrário.

Senti-me atraída pelo grupo 'fábrica de idéias' imediatamente. Talvez por usarem sucata, tintas e também porque sentimo-nos à vontade entre os coordenadores.

Com o passar do tempo, percebemos que esta atração tinha como ponto - chave o fato de os coordenadores terem formações diferentes (um psiquiatra, um psicólogo e um terapeuta ocupacional) e conseguirem trabalhar tão bem, juntos.

Essa observação determinou o tema da monografia que teve como sujeitos do estudo, os coordenadores desse grupo.

Durante o desenvolvimento do estágio e desse estudo, pudemos perceber que a enfermeira tem um papel definido, um trabalho respeitado, um contato direto com o paciente, boa relação com a equipe. Pode-se afirmar que o modo como a enfermeira se insere na instituição e o papel que exerce é inovador para os sujeitos deste estudo. Inovador no sentido de inédito e transformador.

Quanto à presença de um estagiário de enfermagem no grupo, foi possivel identificar a "indiferença" quanto à especificidade profissional (poderia ser um estagiário de T. O; ou de psicologia). Chamou-nos a atenção o fato de que para essa equipe, a Saúde Mental é um novo caminho para a enfermagem seguir.
Outra questão importante é a equipe interdisciplinar. Foi uma experiência gratificante ver uma equipe que trabalhava desse modo não compartimentado.

O grupo coordenador, sujeito deste estudo, valoriza a importância da questão interdisciplinar, porém, quando se remetem a conceitos teóricos, percebe-se que isto não está bem claro. Mas, no que se refere ao trabalho em si, a interdisciplinaridade é colocada em prática com perfeição, fazendo com que os três se mesclem de tal maneira que fica dificil diferenciá-los profissionalmente.

A equipe identifica no próprio grupo "fábrica de idéias" o modelo assistencial do CAPS: mudança de paradigmas, olhar voltado para o sujeito enquanto produtor de necessidades e possibilidades e intermediação entre o terapêutico e o social. A noção de reabilitação psicossocial está presente.

Para as autoras, esta experiência foi valiosíssima, principalmente por ver o quanto a enfermeira pode superar os limites impostos por hospitais, médicos e pela sociedade; e como uma equipe que trabalha deste modo, não compartimentado, não especificando funções, funciona de forma mais produtiva, aprendendo e dividindo experiências e saberes.

\section{REFERÊNCIAS BIBLIOGRÁFICAS}

ALMEIDA, MCP; ROCHA, JSY. O saber de enfermagem e sua dimensão prática. São Paulo: Cortez, 1986.

AMARAL, AMM do. A enfermagem psiquiátrica na realidade brasileira: desafío entre o saber e o fazer. Rio de Janeiro, 1990. 141p. Dissertação (Mestrado) - Escola de Enfermagem Ana Nery, Universidade Federal do Rio de Janeiro.

BARIÇÃO, SMF. Centro de atenção psicossocial: construindo um projeto. Saúde Atual. v.1, n.1 , 1994.

BARROS, S. O louco, a loucura e a alienação institucional: o ensino de enfermagem psiquiátrica sub júdice. São Paulo.1996, 202p. Tese (Doutorado). Escola de Enfermagem, Universidade de São Paulo.

BARROS, S. et al. Tentativas inovadoras nas práticas de ensino e assistência. /Trabalho apresentado no $3^{\circ}$ Congresso Nacional da Rede Unida. Salvador, 1997.

BERG, JHV. O paciente psiquiátrico. São Paulo: Mestre Jaw, 1981.

CAMPOS, MA. O trabalho em equipe multiprofissional: uma reflexão crítica. Ribeirao Preto, 1990.

FILIZOLA, CLA. O papel do enfermeiro psiquiátrico: oprimido e opressor. São Paulo, 1990, 149p. Dissertação (Mestrado). Escola de Enfermagem, Universidade de São Paulo. 
GOLDBERG, JI. Reabilitação como processo: o Centro de Atenção Psicossocial - CAPS. In: PITTA, A (org.) Reabilitação psicossocial no Brasil. São Paulo: Hucitec, 1996. p.33-47.

MINAYO, MCS. O desafio do conhecimento: pesquisa qualitativa em saúde. São Paulo: Hucitec - Abrasco, 1992.

OLIVEIRA, FB; JORGE, MSB; SILVA, WV. Centro de atenção psicossocial: a reinvenção da prática da enfermeira. In: CONGRESSO BRASILEIRO DE ENFERMAGEM, 48. Livro Programa. São Paulo, ABEn-SP, 1996. p.349.

PEPLAU, HE. Interpersonal techniques: the crux of psychiatric nursing. Amer J Nurs, v.6, n.6, p.50-60, 1962.

PITTA, AMF et al. Projeto de integração docente assistencial em reabilitação psicossocial. São Paulo: 1994. (mimeografado)

POLIT, DF; HUNGLER, BP Fundamentos de pesquisa em enfermagem. 3.ed. Porto Alegre: Artes Médicas, 1995.
ROCHA, RM. Enfermagem psiquiátrica: que papel é este? Rio de Janeiro. 1992, 173p. Tese (Doutorado) - Instituto de Medicina Social, Universidade do Estado do Rio de Janeiro.

SARACENO, B. Teorias e modelos em reabilitação. Trad. Ana Luísa Aranha e Silva e Marina Peduzzi. São Paulo, 1994. (Mimeografado)

SANTOS, BS. Um discurso sobre as ciências. 2.ed. Lisboa: Afrontamento, 1988.

SILVA, ALA; FONSECA, RMG. Repensando o trabalho em saúde mental: a questão da interdisciplinaridade. Recife: 1993. (mimeografado).

SILVA, ALA. O projeto copiadora do CAPS: do trabalho de reprodução de coisas à produção de vida. São Paulo, 1997. 131p. Dissertação (Mestrado). Escola de Enfermagem, Universidade de São Paulo.

\section{ANEXO}

Instrumento de coleta de dados utilizado na entrevista:

1. Qual é a sua concepção de interdisciplinaridade?

2. Como surgiu a proposta do projeto "fábrica de idéias"?

3. Quais são os objetivos definidos para o projeto "fábrica de idéias"?

4. Como este projeto se insere no modelo do CAPS?

5. Como você vê a inserção de um estudante de enfermagem no projeto? 